\title{
Analysis of Construction Cost Fluctuation Trends and Features on Apartment Housing
}

\author{
Park, Wonyoung Kang, Tai-Kyung Baek, Seung-Ho Lee, Yoo-Sub* \\ Construction Management - Economic Research Division, Korea Institute of Construction Technology, \\ Ilsanseo-Gu, Goyang-Si, Gyeonggi-Do, 411-712, Korea
}

\begin{abstract}
Construction projects, including housing, are carried out over long periods of time. According to changes to the construction period, the cost of input materials and wages also changes. Therefore appropriate management is important in order to minimize cost risks caused by fluctuations in prices. In Korea, housing units are usually sold in lots prior to construction completion. Therefore, careful management of input elements such as materials and equipment that are sensitive to price fluctuations is very important. This study deals with how the price fluctuation of materials, labor, and equipment influences the change of housing cost and seeks a way for cost management through identifying key resources sensitive to price fluctuation. As a result, a change to the housing cost index multiplies depending on cost changes of materials and labor together. Labor costs are a major factor on the housing cost index. In addition, certain types of materials and labor input to housing construction greatly influence price fluctuations. Thus, it is found that managing those main cost factors is the key for effective cost management
\end{abstract}

Keywords : construction cost index, price fluctuation, resource management

\section{Introduction}

\subsection{Research background and objective}

In Korea, housing problems started to be remedied since industrialization began in the 1960s, and the keynote of housing policy has since been driven differently depending on the aspects of housing problems by period. The biggest feature in Korea's system and policy in terms of the supply of apartment houses is to implement a system of a lot-sold price cap to regulate lot-sold pricing in order to stabilize the lot-sold price of apartment housing, along with an advanced lot-sold system to be sold in lots prior to the completion of

Received : August 20, 2012

Revision received : November 15, 2012

Accepted : November 20, 2012

* Corresponding author: Lee, Yoo-Sub

[Tel: 82-31-910-0417, E-mail: yslee1@kict.re.kr]

(c)2012 The Korea Institute of Building Construction, All rights reserved. construction. The lot-sold price cap system means a systematic measure to determine the lot-sold price to be within a certain boundary linking the land price and construction cost, so the system restricts sharp increases to the lot-sold price, provides the end user with an opportunity to buy the house fairly compared to the price level of the surrounding area and becomes a policy keynote to contribute to the price stability of an ordinary house[1].

The lot-sold price in the lot-sold price cap system is calculated by dividing the price into land cost and construction costs: the land cost is calculated by applying the land supply price or the price of appraisal and assessment while the construction cost, based on a basic-type construction cost notified by the government, thus the final lot-sold price cap is decided[2]. Accordingly, the government is notifying the basic-type construction cost, a base of construction 
cost calculation, and the basic-type construction cost is then adjusted and notified according to the price fluctuation by using the construction cost index of apartment housing(housing construction cost index) every 6months in order to make it dynamic according to market situations.

The housing construction costs in the price cap system is calculated based on the basic-type construction cost notified by the government at the time of project approval, so it applies the construction cost reflecting the price in the lot-sold time, but the price fluctuation from the lot-sold time to construction completion is not considered. Especially, the housing supplier dedicated to redevelopment and rebuilding, including a private housing association, as well as a public housing suppler doesn't recognize the adjustment of the lot-sold price depending on price fluctuations at the time of the determined lot-sold price. Given the recent trend that the cost rate of housing construction increases while the profits gradually decreases, it is required to minimize cost risk factors depending on price fluctuations by properly managing items sensitive to price fluctuation during the construction period.

Kim mentions that Construction Cost Index is the useful tool which identifies trends in the construction industry, analysis the flow of the market, and can be utilized for the purpose of cost[3].

This purpose of this study is to grasp the fluctuation trend of the housing construction cost index over approximately 5years from the time that the basic-type construction cost is set to the present and to identify detailed expenditure items, the contribution of index fluctuations by item, the main materials that are sensitive to price fluctuation and features of the labor category.

\subsection{Research scope and method}

The construction work, including housing, progresses over long-term periods, and the price of input materials and labor fluctuates as time passes, so it is required to correctly manage such in order to minimize cost risks depending on price fluctuations. In the case of implementing the advanced lot-sold system for housing supply like in Korea, the lot-sold price is determined prior to the completion of construction, therefore it is required to properly manage construction elements, including materials and items sensitive to price fluctuations during the housing construction period

Analyzing the effects that price fluctuations of materials, labor force and device input to construction has on housing construction cost fluctuations and identifying the main resources sensitive to this, this study attempts to determine how to manage costs. For this purpose, reviewing the items and features of the housing construction cost index and analyzing trends of the index fluctuation and contribution by expenditure item composed of the housing construction cost index, it tries to identify the implications. In addition, identifying the items that cause fluctuation of the housing construction cost index and reviewing the effect that they have on the housing price fluctuation, it tries to present a method to manage the housing construction cost depending on the actual price fluctuation.

In this analysis, targeted on a model house using calculation of basic-type construction cost by the Ministry of Land, Transportation and Maritime Affairs, the detailed input items are identified and the trends of price fluctuations were analyzed in depth. In the case where the finishing materials and so on differ depending on housing complexes, a difference in price fluctuation may occur, but because the model houses used in this study meet 
the current housing design standards and specifications, this analysis could be meaningful for identifying the trends and features of price fluctuations in general lot-sold housing.

\section{Status and feature of housing construction} cost index

\subsection{Review of previous research}

When it comes to existing studies related to the construction cost index, such can be classified into a study concerning the construction cost index development and a study concerning cost forecasting model development, and the key contents of those studies are shown in Table 1. Existing study literature focused on developing the index for multiple purposes in order to identify the fluctuation index of construction costs as well as housing price or to develop a statistical model for forecasting the index.

Table 1. Literature review

\begin{tabular}{|c|c|c|}
\hline Field & Author & Substance \\
\hline $\begin{array}{c}\text { Development } \\
\text { of } \\
\text { construction } \\
\text { price index }\end{array}$ & $\begin{array}{l}\text { Cho et } \\
\text { al.[5] } \\
\text { Lee et } \\
\text { al.[6] }\end{array}$ & $\begin{array}{c}\text { Development of construction index for } \\
\text { price adjustment of standard price in } \\
\text { apartment housing } \\
\text { Development of index model for } \\
\text { escalation of price adjustment rate } \\
\text { Development of construction cost } \\
\text { index based on connecting } \\
\text { "Input-output table" and "Producer } \\
\text { Price Index" }\end{array}$ \\
\hline $\begin{array}{l}\text { Forecasting } \\
\text { model for } \\
\text { construction } \\
\text { prices }\end{array}$ & $\begin{array}{l}\text { Cho et } \\
\text { al.[7] } \\
\text { Cho et } \\
\text { al.[8] } \\
\text { Kim et } \\
\text { al.[9] }\end{array}$ & $\begin{array}{l}\text { Building statistical forecasting model } \\
\text { through time series analysis } \\
\text { Building construction cost forecasting } \\
\text { model using artificial neural networks } \\
\text { Estimation of the construction cost } \\
\text { index by using the hybrid time series } \\
\text { model(ARIMA) }\end{array}$ \\
\hline
\end{tabular}

However, because in-depth studies on index fluctuation trends and the patterns and features of index fluctuation by input element are insufficient thus far, this study attempts to concretely analyze the index fluctuation by input element based on the housing construction cost index developed for updating basic-type construction costs. The outcome is anticipated to contribute to determining how manage key resources.

\subsection{Structure of housing construction cost index}

Time is a key factor that causes the construction cost to fluctuate, so in order to grasp the trend of construction cost fluctuation depending on time flow, the value of a certain time should be calculated by using the price index of input elements by item of housing construction costs, or the construction cost index of apartment housing[10]. Price means a general price level averaged by considering the individual product price traded at market price through the importance placed on economic life and is expressed as one figure so that one can recognize any price fluctuation at a glance.

The current government is using a standard to update the basic-type construction cost every 6months by developing a construction cost index for apartment housing, so a process to calculate the index corresponding to the revision of basic-type construction cost calculation standard in 2007 is as shown in Figure1.

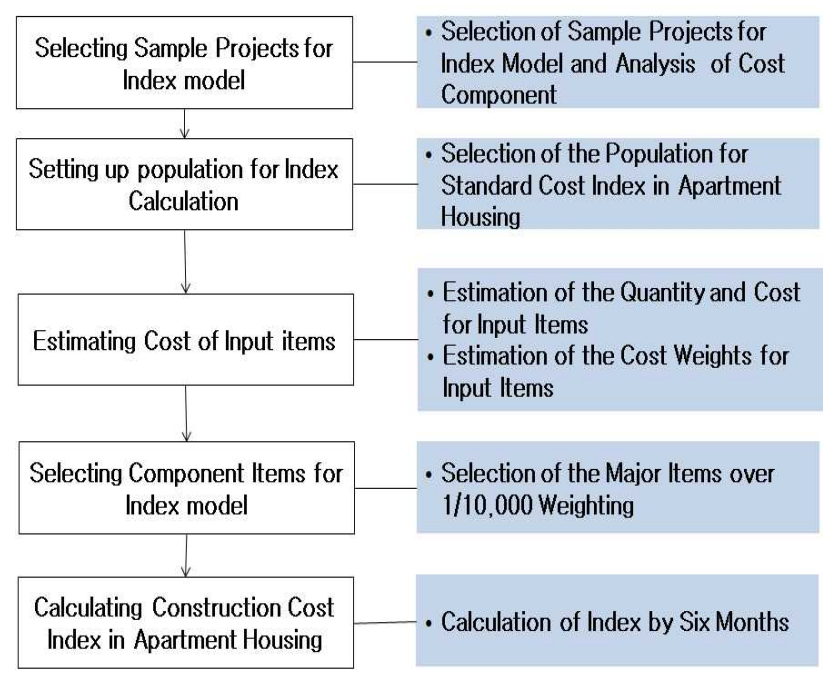

Figure 1. Calculation process of construction cost index 


\subsubsection{Structure of index calculation}

A standard element method, which is now being used extensively home and abroad, applied the index calculation method. The standard element method(or a lexical disassembly method) means a way to select a project of a standard model, to decide the weighted value of items input to the project and to update the index by monitoring the price changes on a regular basis[11]. This model project was developed targeting on the model houses selected in order for the government to notify the basic-type construction cost in 2007, and the model project to analyze the item-specific weighted value was developed by selecting the same houses used for calculating the basic-type construction cost and then by analyzing these items under the index and the weighted value.

\subsubsection{Items of index calculation}

The selection of items for index organization is limited to the largely weighted ones compared to the cut-off method, or a purposed sample method. Now our nation is considering the trade amount, the representative attribute of price fluctuation, the continuity of quality and standards, etc., and in the case where items with a volume of more than $1 / 10,000$ of weighted population equal to the weight applied to the price index of a producer are selected as input ones, with 638 out a total of 4,283 composing the direct construction cost being selected, and thus it is possible to explain $81.1 \%(=86.3 \% \times 94.0 \%$ : The items related to the index accounts for $86.3 \%$ of the total direct construction cost and the assumption ratio of indirect cost by using the direct construction cost of 94\%)of basic-type construction costs.

Out of these, labor items are composed of 50 items, including framing carpenter, concrete laborer, piping engineer and general laborer, 536 material items, including rebar, ready-mix concrete and PHC file, and expenditure items, including 52 heavy machinery devices including dump trucks and concrete dump vehicles.

\subsubsection{Weighted value and price data}

In the case where items calculated into index organization are selected, the final weighted value for calculating the index for those items is determined. As mentioned in the above section, the final weighted value for calculating the index is decided for 648 items with a weighted value more than 1/10,000 including indirect construction costs. The volume is then decided at the same time with standard model setting, but the price may differ dependent on the data used. Components used for the organization of housing construction cost index are labor costs, materials costs and machinery expenditures.

First, when it comes to labor costs, the weighted value structure of this is calculated based on the standard model project, so the weighted value structure was calculated by using the result. In addition, when it comes to the price data on material costs and machinery expenditures, in order to secure the reflection of the actual trade price, public confidence and regularly updated data, the Supply Administration and $\mathrm{LH}$ Corporation's self-inspection price on actual trade was used.

Table 2. Fluctuation of construction cost index

\begin{tabular}{|c|c|c|c|}
\hline Date & Index & Date & Index \\
\hline '07.9.1 & 100 & '10.3.1 & $\begin{array}{l}111.97 \\
(1.81 \%)\end{array}$ \\
\hline '08.3.1 & $\begin{array}{c}102.16 \\
(2.16 \%)\end{array}$ & '10.9.1 & $\begin{array}{c}113.31 \\
(1.20 \%)\end{array}$ \\
\hline '08.9.1 & $\begin{array}{c}110.02 \\
(3.16 \%)\end{array}$ & '11.3.1 & $\begin{array}{l}114.97 \\
(1.46 \%)\end{array}$ \\
\hline '09.3.1 & $\begin{array}{c}109.91 \\
(\triangle 0.11 \%)\end{array}$ & '11.9.1 & $\begin{array}{l}117.25 \\
(1.98 \%)\end{array}$ \\
\hline '09.9.1 & $\begin{array}{c}109.98 \\
(0.07 \%)\end{array}$ & '12.3.1 & $\begin{array}{l}119.78 \\
(2.16 \%)\end{array}$ \\
\hline
\end{tabular}


Also, in order to minimize the distortion of price structure caused by seasonal change, the reference point was set by taking an average on the time series data for a certain period.

The index is calculated by using Laspeyres's modified formula through the index development process, and when it comes to index fluctuation, according the recalculation result of an index item-specific price and spent-manpower notified for the first time as shown in Table2, basic-type construction costs now increased by $19.78 \%$ compared to the first $\operatorname{cost}(100)$ notified on September 1, 2007, thus the construction cost index of apartment housing is shown at 119.78p.

\section{Trend of the price fluctuation of housing construction cost}

\subsection{Trend of the housing price index fluctuation}

Korea's representative price index refers to the producer price index and the consumer price index as issued by the Bank of Korea: the former is often used to calculate the fluctuation rate of some material items in order to adjust the earnest money through price fluctuation in the process of construction contract performance[12]. However, because items input to the index organization and the weighted value structure do not reflect the features of apartment housing when using the producer price index in order to identify the fluctuation trends of the standard price of a certain structure, such as basic-type construction costs over time, an extra index is being used. Therefore, the current basic-type construction costs are regulated to be updated every 6months by using the housing construction cost index reflecting the features of apartment housing.

According to Figure2, which shows the fluctuation trend of the housing construction cost index from September 2007 to the present when the basic-type construction costs was publicized for the first time, it was found to increase by about 20\% over the last 5years. The housing construction cost index fluctuation for the same period is shown to have increased by about $8 \%$ sharply for 9months from March 2008, which is due to the increased price of rebar, a key construction material, caused by the drastic increase of international raw resource pricing, including rebar, etc. increased the overall general construction cost. As such, the increase rate of the housing construction cost index for the same period was similar to the producer price index, but the fluctuation trend by period is shown be slightly different. For example, the producer price index from September 2008 to March 2009 decreased by about 4\%, but the housing construction cost index rarely fluctuated, which is because of the interrelationship between the input structure of items spent on housing construction and period-specific price fluctuation. In other words, the producer price index is sensitive to the fluctuation of material pricing with a high weighted value while the housing construction cost index is complexly dependent on labor costs and indirect construction costs, as well as the fluctuation of material prices.

As such, housing construction costs is quite similar to the producer price index, but there is some difference in detailed period-specific index fluctuation. That is because of the difference of items input to housing and period-specific actual trade prices, thus it is required identify features by input element through reviewing the contribution having an effect on the decision of the housing construction cost index by input element in housing projects. 


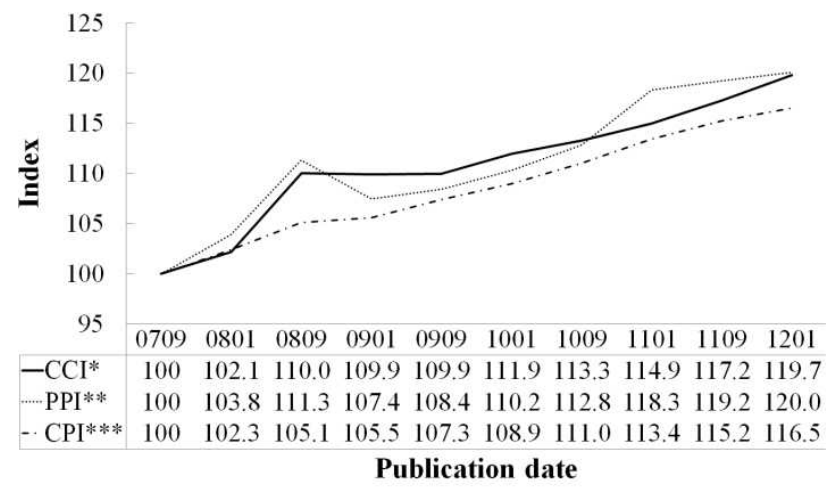

* Construction Cost Index

** Producer Price Index (The Bank of Korea)

$* * *$ Consumer Price Index (The Bank of Korea)

Figure 2. Comparison of indices fluctuation

\subsection{Trend of price fluctuation by items of expenditure}

When it comes to the current housing construction cost index, the index can be calculated by inspecting the item-specific actual price every 6 months by extracting 638 items with a weighted value of $1 / 10,000$ out of the total of 4,283 items, composing the basic-type construction costs for operating the lot-sold price cap. To divide the housing construction cost index by item, labor-related items are composed of 50 job types including framing carpenter, concrete laborer, piping engineer and general laborer, and the 536 material cost related items including rebar, ready-mix concrete and $\mathrm{PHC}$ file. In addition, direct expenditure items, including machinery, includes 52 devices such as dump trucks and concrete placing vehicles, and expenditure items including indirect labor costs and safety management costs input indirectly for building the construction purpose as well. Hereinafter, the expenditure item-specific price fluctuation trends and features will be observed.

\subsubsection{Labor costs}

To observe Figure3 which shows the price fluctuation trend of labor costs related items composing the housing construction cost, it is steadily on the increase every year. When it comes to price information by labor type, the labor cost fluctuation is calculated by applying the weighted value and labor costs by job input to housing construction by using the open labor cost as publicized by the Construction Association of Korea. The labor cost was found to increase by about $22.7 \%$ over the last 5years and it can be interpreted that the cost of labor input to housing construction increased annually by about $5.4 \%$.

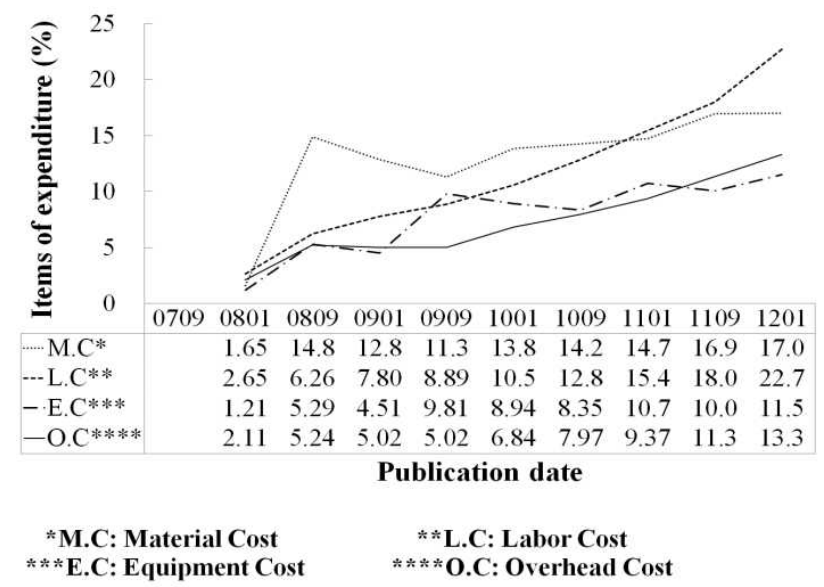

Figure 3. Fluctuations of items of expenditure

In addition, the fluctuation of labor costs has also an effect on that of indirect costs composed of each kind of premium. The indirect costs calculated by the rate compared to labor costs for the same period was also found to increase by $20.57 \%$ similarly to labor costs. As such, labor costs in a housing project has a big effect on price fluctuation, thus it is required to prepare for a safe demand/supply management chain in terms of labor power sensitive to price fluctuation through in-depth identification of key labor types input to housing.

\subsubsection{Material cost}

When it comes to price fluctuations of material items, it showed a trend of sharp price increases 
from March to September 2008, but thereafter general pricing stabilized with some material prices actually having decreased. The construction cost increases mainly by rebar cost and so on influenced by import prices according to the sharp increase of the international raw resource price of rebar and so on due to an increase of demand for developing nations such as China, India and the Middle East at that time. In order to respond to this situation, with regards to rebar and so on, which are important materials for housing construction costs and dependent on importation, it is required to place effort to increase productivity and to reduce costs while observing the price trend of international raw resources. In addition, given the entire fluctuation trend of housing material cost shows a similar fluctuation pattern to the producer price index, it is also desirable to manage the price of housing materials in conjunction with the producer price index.

\subsubsection{Equipment expenditure}

When it comes to equipment expenditure, it showed the trend of price increase around 11\% over the last 5 years, and also the repeated feature of period-specific fluctuation. The device price, or an element for calculating device expenditures, has an effect on the fluctuation of such, and especially items imported from foreign nations are dependent on the exchange rate in terms of the actual end price. In other words, the period-specific exchange rate fluctuation is a cause for fluctuations in foreign-made products and materials, which results in a fluctuation in terms of device expenditures and rent.

To arrange the fluctuation trend of housing prices by expenditure item as such, the labor costs shows a steady increase every year while material costs are largely dependent on the price trends of international raw resources every period, and device expenditures showed a repeated feature of period-specific fluctuation dependent on the exchange rate.

\subsection{Contribution ratio of the index fluctuation by expenditure item}

To observe Figure4 in terms of the contribution ratio(Percentage on the index increase/decrease depending on the fluctuation of each item) having an effect on the index fluctuation by item while the housing construction cost index fluctuated by 19.78\% over the last 5years, it was found that for the same time period that labor costs that increased by $22.7 \%$ contributed to the overall index increase by $8.27 \%$, material costs increased by $17.0 \%$, by $6.09 \%$ and indirect construction costs increased by $13.3 \%$, by $5.07 \%$. The direct expenditure including device costs increased by $11.51 \%$, but contributed to index fluctuation by $0.36 \%$, thus it was found that the price fluctuation of direct expenditure had only a slight effect on the overall index fluctuation.

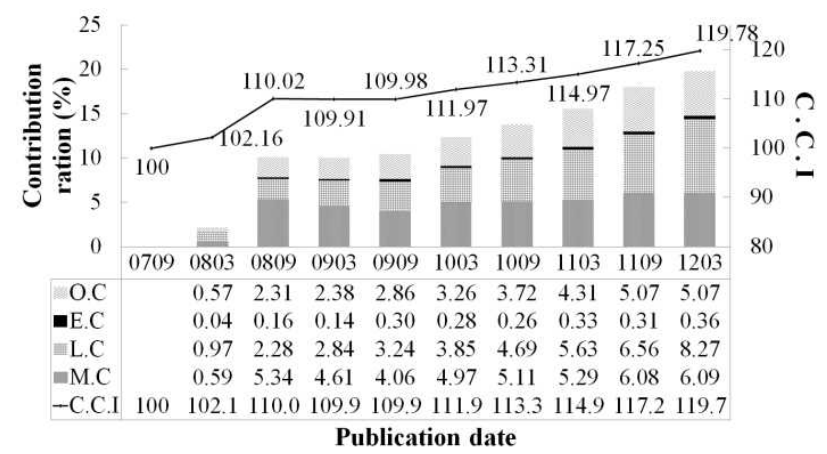

Figure 4. Contribution ratio of items of expenditure

As such, when it comes to fluctuation of the housing construction cost index, it was found that increased labor costs contributed to the index fluctuation by about $8.27 \%$ and indirect construction costs calculated in conjunction with labor costs contributed to the index increase by $5.07 \%$, so it is assumed that the increased labor costs 
directly/indirectly contributed to the index increase by about $13 \%$. This value is equal to about $65 \%$ of the total fluctuation of the housing construction cost index: it was found that labor costs largely contributed to the fluctuation of the housing construction cost index for the time being. In addition, given the weight that material costs accounts for in a housing project, it is seen that fluctuations in material costs also has a big effect on index fluctuation, thus it is required to determine how to analyze and manage in detail material items that are sensitive to price fluctuation.

\section{Analysis on the contribution and features of item-specific index fluctuations}

\subsection{Labor type-specific contribution and feature}

The labor types input for calculating the current housing construction cost index are composed of a total of 50, so to observe the job type-specific index having a large effect on type-specific index fluctuations, it was found that about 10 labor types contributed to the labor index fluctuation by about $74 \%$ over the last 5years. As such, there are a variety of labor types input to housing construction, but it can be known that only some types have any effect on price fluctuation.

As such, to observe labor types that contribute largely to the fluctuation of the labor cost index every 6 months considering a few job types have contributed significantly to the construction cost index, general laborers have the biggest effect on the index fluctuation as seen in Table3 and are followed by framing carpenters and internal line engineers. Especially, the standard deviation of general laborers and internal line engineers is small, so they are shown to pull the increase of labor costs every 6months.

The weight of general laborers, framing carpenters and internal line engineers in housing construction is high and the fluctuation of those jobs results in a fluctuation of the entire housing construction cost, so it can be known that stable demand/supply management of labor force in all types of labor jobs, including general laborers, can increase the efficiency of cost management.

In addition, it was found that to prepare for a strategic measure for training and securing relevant manpower in advance in order to stabilize the supply and demand of laborers through the construction process is efficient to manage risk caused by sharp cost fluctuations.

Table 3. Contribution ratio of major labor occupations

\begin{tabular}{|c|c|c|c|c|c|c|c|c|c|c|c|}
\hline $\begin{array}{l}\text { Occupational } \\
\text { classification }\end{array}$ & '08.3 & '08.9 & '09.3 & '09.9 & '10.3 & '10.9 & '11.3 & $' 11.9$ & '12.3 & av. & S.D. \\
\hline Laborer(9) & 0.233 & 0.388 & 0.330 & 0.166 & 0.134 & 0.192 & 0.237 & 0.193 & 0.190 & 0.229 & 0.081 \\
\hline Carpenter(9) & 0.148 & 0.058 & 0.178 & 0.078 & 0.062 & 0.065 & 0.126 & 0.078 & 0.440 & 0.137 & 0.121 \\
\hline Electrician(9) & 0.083 & 0.082 & 0.094 & 0.089 & 0.135 & 0.192 & 0.158 & 0.081 & 0.169 & 0.120 & 0.044 \\
\hline $\begin{array}{l}\text { Reinforcing bar } \\
\text { placer(8) }\end{array}$ & 0.013 & 0.137 & 0.114 & 0.030 & 0.029 & 0.058 & 0.022 & 0.041 & 0.089 & 0.059 & 0.044 \\
\hline Plumber(6) & 0.086 & 0.074 & 0.015 & 0.019 & 0.075 & 0.034 & 0.030 & 0.027 & 0.018 & 0.042 & 0.028 \\
\hline $\begin{array}{c}\text { Communication } \\
\text { technician(9) }\end{array}$ & 0.038 & 0.025 & 0.028 & 0.015 & 0.047 & 0.054 & 0.041 & 0.033 & 0.056 & 0.037 & 0.014 \\
\hline Bricklayers(6) & 0.013 & 0.047 & 0.020 & 0.011 & 0.049 & 0.040 & 0.017 & 0.022 & 0.039 & 0.029 & 0.015 \\
\hline Plasterer6) & 0.013 & 0.049 & 0.006 & 0.008 & 0.021 & 0.035 & 0.030 & 0.034 & 0.053 & 0.028 & 0.017 \\
\hline Skilled labor(4) & 0.028 & 0.009 & 0.026 & 0.006 & 0.008 & 0.046 & 0.026 & 0.020 & 0.015 & 0.020 & 0.013 \\
\hline Welder(3) & 0.013 & 0.035 & 0.006 & 0.006 & 0.045 & 0.003 & 0.010 & 0.041 & 0.023 & 0.020 & 0.016 \\
\hline Contribution ratio & 0.669 & 0.905 & 0.816 & 0.428 & 0.605 & 0.719 & 0.697 & 0.570 & 1.093 & $\begin{array}{l}6.504 \\
\text { (Total) }\end{array}$ & $\begin{array}{c}\text { (Absolute } \\
\text { value) }\end{array}$ \\
\hline Percentage & $67 \%$ & $80 \%$ & $73 \%$ & $78 \%$ & $70 \%$ & $74 \%$ & $83 \%$ & $65 \%$ & $75 \%$ & $74 \%$ & \\
\hline
\end{tabular}




\subsection{Contribution by material item}

To observe the effect on the index fluctuation of each material item of a total of 500 ones used to for the index calculation out of the items composing the material costs for the last 5years through Pareto's curve, some certain materials had a large effect on the overall index fluctuation similarly to labor costs.

As such, to observe the material items that contribute largely to the fluctuation of the material cost index every 6months considering a few types of material items have contributed significantly to the construction cost index, rebar had the biggest effect on the index fluctuation as seen in Table4 and are followed by ready-mix concrete and copper pipe. Especially, key materials including rebar, ready-mix concrete and copper pipe are high in the weight of construction costs and show a standard deviation of index fluctuation, so it is found that the fluctuation level is high depending on the period.

The standard-specific rebar, which plays a basic role to calculate the housing construction cost index out of required main materials, increased on average by $21.6 \%$ and the total amount of rebar material cost, by $57.2 \%$, so it contributed to an index increase of $1.27 \%$. According to the index by high-tensile rebar item out of the producer price index publicized by the Bank of Korea, it increased by $50.9 \%$ for the same period, so the fluctuation trend of both indices is similar in Figure5.

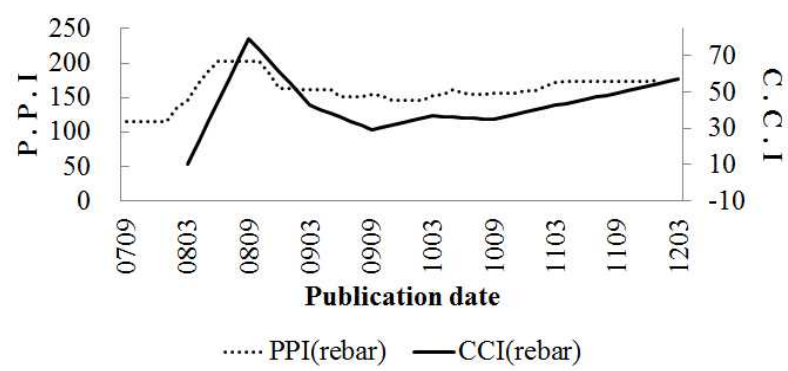

Figure 5. Features of rebar cost fluctuation

In addition, according to the analysis of the fluctuation of copper tube costs, standard-specific average costs increased by $21.8 \%$ and the total amount of material costs by $21.4 \%$, so it was found that it contributed to an increase of the construction cost index by $0.21 \%$. When it comes to copper tube, according to the analysis of it with the producer price index, it was found that the fluctuation was reflected without a time gap. Figure6 shows the comparison between the increased rate of copper tube costs in the housing

Table 4. Contribution ratio of major material items

\begin{tabular}{|c|c|c|c|c|c|c|c|c|c|c|c|}
\hline & '08.3 & '08.9 & '09.3 & '09.9 & 10.3 & '10.9 & '11.3 & $' 11.9$ & '12.3 & av. & S.D. \\
\hline Rebar(9) & 0.538 & 0.037 & 1.783 & 0.660 & 0.367 & 0.101 & 0.359 & 0.318 & 0.342 & 0.501 & 0.517 \\
\hline $\begin{array}{l}\text { Ready mixed } \\
\text { concrete(6) }\end{array}$ & 0.000 & 0.139 & 0.435 & 0.065 & 0.229 & 0.014 & 0.005 & 0.084 & 0.508 & 0.164 & 0.190 \\
\hline Copper pipe(7) & 0.000 & 0.148 & 0.469 & 0.197 & 0.258 & 0.070 & 0.096 & 0.108 & 0.000 & 0.150 & 0.147 \\
\hline Panel(6) & 0.022 & 0.037 & 0.209 & 0.064 & 0.061 & 0.028 & 0.000 & 0.078 & 0.000 & 0.056 & 0.064 \\
\hline PHC pile(6) & 0.005 & 0.118 & 0.154 & 0.000 & 0.077 & 0.028 & 0.000 & 0.027 & 0.021 & 0.048 & 0.056 \\
\hline Pair glass(5) & 0.000 & 0.030 & 0.078 & 0.000 & 0.000 & 0.010 & 0.120 & 0.000 & 0.036 & 0.275 & 0.031 \\
\hline Diesel(3) & 0.049 & 0.024 & 0.033 & 0.012 & 0.015 & 0.023 & 0.045 & 0.005 & 0.007 & 0.214 & 0.024 \\
\hline Rectangular timber(2) & 0.000 & 0.003 & 0.100 & 0.000 & 0.000 & 0.009 & 0.000 & 0.093 & 0.010 & 0.212 & 0.024 \\
\hline Contribution ratio & 0.614 & 0.532 & 3.261 & 0.998 & 1.008 & 0.284 & 0.625 & 0.714 & 0.924 & $\begin{array}{l}8.960 \\
\text { (Total) }\end{array}$ & $\begin{array}{c}\text { (Absolute } \\
\text { value) }\end{array}$ \\
\hline Percentage & $66 \%$ & $41 \%$ & $76 \%$ & $68 \%$ & $78 \%$ & $33 \%$ & $59 \%$ & $81 \%$ & $77 \%$ & $67 \%$ & \\
\hline
\end{tabular}


construction cost index and the copper tube index of the producer price index

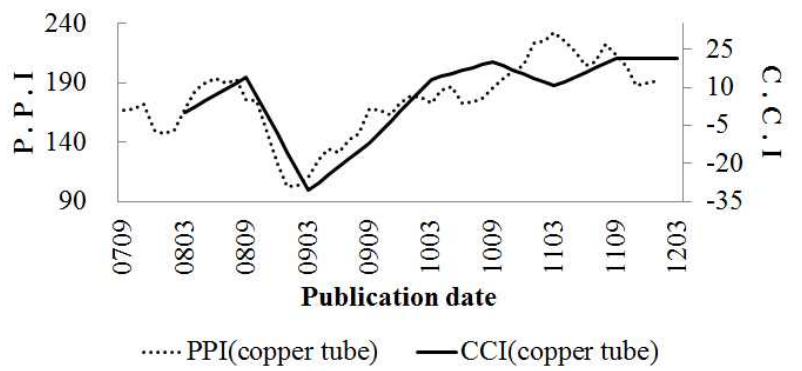

Figure 6. Features of copper tube cost fluctuation

According to the comparison of the fluctuation between the producer price index and construction costs index, it can be known that the fluctuation of the producer price index was reflected to the housing price index after 6months. Figure7 shows the comparison between the increased rate of ready-mix concrete costs in the housing construction cost index and the ready-mix concrete index of the producer price index: it can be known that the fluctuation trends are similar every 6months except for the last 6months.

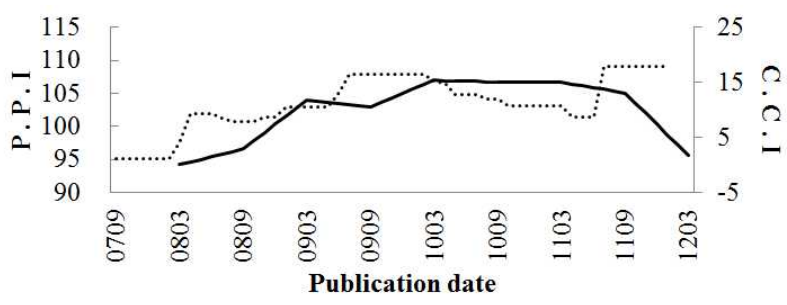

.......PPI(ready-mixed conc.) - $\quad$ CCI(ready-mixed conc.)

Figure 7. Features of ready-mixed conc. cost fluctuation

The material costs for PHC file increased on average by $20.1 \%$ by standard for the same period and the total amount of PHC file material costs, by 19.8\%: it contributed to an increase of the construction cost index by $0.21 \%$. As seen in Figure8, PHC file also showed a similar fluctuation between the producer price index of concrete file and the PHC file material of the construction costs index at an interval of 6months, similar to the ready-mix concrete. This means that the fluctuation of PHC file price has an effect on the fluctuation of construction costs at the regular periodical intervals. When it comes to oil costs, it was found that gasoline and light oil increased by $43.94 \%$ and $55.45 \%$ respectively and contributed to increase of the construction cost index by $0.11 \%$, but because an increase of oil cost pulls from that of device expenditure, it is found that the actual increase of oil costs has a larger effect on the overall increase of the index than the identified value.

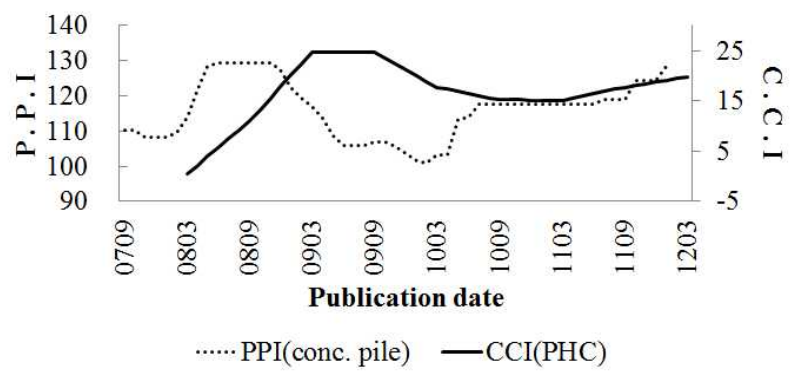

Figure 8. Features of PHC pile cost fluctuation

As such, when it comes to materials, it can be found that the fluctuation of items produced through the direct process of raw materials such as rebar and copper pipe, has a direct effect on construction costs, while price fluctuations of products produced through the manufacturing process such as ready-mix concrete and concrete file occurred in conjunction with the time interval. Accordingly, because the material cost fluctuation of products like copper pipe results directly in a price increase of the production spot, it is possible to increase the efficiency of cost management with regards to main materials through the creation of supply and demand management system for materials in order to continually identify the trends of international material pricing, including import pricing. 


\section{Conclusion}

Analyzing the effect that the price fluctuation of materials, labor force and device input to construction has on the overall housing construction cost fluctuation and identifying main input that are elements sensitive to price fluctuation, this study attempted to analyze the feature of price fluctuations of those input elements.

According to the above analysis, the implications can be acquired as follows: First, the housing construction price over the last 5years showed similar fluctuation trends and increased rates as the producer prices, but there is some difference in the detailed period-specific price fluctuation. This means that because the producer price is sensitive to the fluctuation of high-weighted material pricing while the index of the housing construction price is influenced complexly by labor costs as well as the fluctuation of material prices, the fluctuation of labor costs has a big effect on that of the housing price.

Second, according to a detailed analysis on the influence of index fluctuations in the price fluctuation of housing projects, it was found that the fluctuation of labor costs contributed to that of the housing construction cost index by more than 65\%. Labor costs have steadily increased on a yearly average of about $5.4 \%$ over the last 5years and around 10 job types, including general laborer, framing carpenter, internal line engineer and rebar engineer out of labor types, contributed to a fluctuation of the labor cost index, so it is anticipated that a stable supply and demand management system can increase the efficiency of cost management.

Third, it is shown that material costs contributed to a fluctuation of the total index by about 30\%, and especially the price fluctuation of some items, including rebar with high-weighted housing construction costs and those dependent on importation out of material items, results in price fluctuation, so it is required to place effort to increase productivity and to reduce pricing while continually observing price fluctuations of international raw resources.

As above, this study tried to identify the input elements sensitive to price fluctuations in housing construction and related features. In this regard, future studies on the management condition of main input elements and the efficient cost management method in the actual construction spot are needed.

\section{References}

1. Lee YS (Construction Cost Research Center, Korea Institute of Construction Technology, Goyang, Korea). Improvement of Standard Price in Apartment Housing. Final report 30 Mar 2007-29 Aug 2007. Gwacheon: Ministry of Construction \& Traffic (Korea): 2007. 90 p. Report No.: KICT2007053. Contract No.: None.

2. Rule for the Estimation of Lot-Sold Price of Apartment Housing, etc. Ministry of Land, Transport and Maritime Affairs No. 447 (March 9, 2012)

3. Kim WY, Kim YJ. Utilizing and Establishing Construction Cost Index by Representative Items. Seoul(Korea): Construction \& Economy Research Institute of Korea. 2009 Oct. 74 p. Report No.: CERIK200903

4. Lee YS (Construction Cost Research Center, Korea Institute of Construction Technology, Goyang, Korea). Development of Construction Cost Index in Apartment Housing. Final report 19 Jul 2005-18 Oct 2005. Gwacheon (Korea): Ministry of Construction \& Traffic (Korea). 2005. 65 p. Report No.: KICT2005045. Contract No.: None.

5. Cho HH, Doe GY. Improvement of Contract Sum Adjustment Method caused by Price Fluctuation using Construction Cost Index. Korean Journal of Construction Engineering and Management. 2005 Feb;6(1):162-68

6. Lee SY, Lee SH. Development of Construction Price Indices, CERIK Working Paper. 1998 May;7(1):1-38. 
7. Cho HH, Park WY, Kang KI. Time Series Analysis and Development of Statistical Forecasting Model for Building Construction Cost Index. Journal of the Architectural Institute of Korea (Structure \& Construction). 2002 Mar;18(3):125-32.

8. Cho HH, Seo DS, Kang KI. Development of Building Construction Cost Forecasting Model Using Artificial Neural Networks. Journal of the Architectural Institute of Korea (Structure \& Construction). 2002 Aug;18(8):107-15.

9. Kim SK, Cho JH. Estimation of the Construction Cost Index by Using the Hybrid Time Series Model: Focused on Apartment Housing Projects. Journal of the Architectural Institute of Korea (Structure \& Construction). 1999 Jul;15(7):127-36.

10. Seeley IH. Building Economics. 4th ed. Hampshire (UK): Macmillan Distribution Ltd; 1996. 224 p.

11. Kincannon L, Franchet Y. Sources and Methods Construction Price Indices. Paris(France): OECD Statistics Directorate. 1998. 142 p. Report No.: 2372435.

12. Lee BD, Park YS. Trend of Producer Price. Seoul (Korea): The Bank of Korea; 2012 Jan. 8 p. Report No.: PPI201201. 